\title{
Food Safety Knowledge and Practice among Community in Sg. Pelek, Sepang, Selangor Darul Ehsan
}

\author{
Nur Ain Mahat, Chong Kok Shi, Sabariah Abd Hamid \\ Faculty of Medicine, Cyberjaya University College of Medical Sciences, Malaysia
}

\section{Article Info \\ Article history: \\ Received Jan 27, 2016 \\ Revised Feb 22, 2016 \\ Accepted Feb 28, 2016}

\section{Keyword:}

Food Safety

Knowledge

Practice

Sepang

\begin{abstract}
Food safety is a basic requirement of food quality. It is an increasingly important public health issue to prevent and control food borne illnesses. A cross-sectional study was designed to determine level of knowledge and practice on food safety, to determine the association between knowledge and practice, and also to identify the association between sociodemographic factors and practice score of the population studied. This study was conducted among adult population in Taman Bahagia, Sungai Pelek, Sepang, Selangor Darul Ehsan. Data were collected using an interviewed structured questionnaire. A stratified random sampling was performed to obtain houses, followed by simple random sampling to select sample in the house. A total of 115 data sets were analysed using Statistical Package for Social Sciences (SPSS) version 20.0. Analysis showed that $35 \%$ of respondents have poor level of knowledge on food safety, whereas $27 \%$ of the respondents have poor level of practices on food safety. Multiple linear regression revealed that there are a significant association between education level $(\mathrm{p}<0.001)$, Adj $\mathrm{b}=2.57$ (95\% CI: 1.15, 3.99) and gender ( $p=0.048)$, Adj $b=1.15$ (95\% CI: 0.01, 2.29) with practice score on food safety. Therefore, health promotion and education on the importance of practicing food safety at home should be focused to prevent further unwanted health effects.
\end{abstract}

Copyright (C) 2016 Institute of Advanced Engineering and Science. All rights reserved.

\section{Corresponding Author:}

Nur Ain Mahat,

Faculty of Medicine,

Cyberjaya University College of Medical Sciences, Malaysia.

Email: ain@cybermed.edu.my

\section{INTRODUCTION}

Food safety is a basic requirement of food quality. It is an increasingly important public health issue to prevent or control food borne illnesses. Food safety is defined as the absence or acceptable and safe levels of contaminants, adulterants, natural toxins or any other components that are detrimental to health on an acute or chronic exposure [1]. The problem is likely to be even more widespread in developing countries where food contamination occurs as a result of poor or inadequate safety practices.

Food borne illnesses, which are preventable, still impose a substantial burden on healthcare systems. In Malaysia, the incidence rate of food poisoning in 2013 was 47.79 per 100,000 populations [2]. Food borne illnesses may further reduce economic productivity if not being prevented [3]. A foodborne outbreak indicates that something in the food safety system needs to be improved.

Many studies on food safety are performed on food handlers in premises rarely done on community population. Therefore, this study was design to determine level of knowledge and practice on food safety, to identify the association between knowledge and practice, and also to determine socio-demographic factors associated with practice score. 


\section{RESEARCH METHOD}

\subsection{Study design and sampling procedure}

A cross-sectional study was conducted in a residential area of Taman Bahagia, which is located in Sg.Pelek, Sepang, Selangor. Stratified random sampling was used to obtain houses and the following simple random sampling used to select respondent in the house. The respondent who did not give consent or unwilling to participate; age below 18 years, a person incapable of answering the questionnaires, nonMalaysians and residents who stayed less than 3 months were excluded from the study. Sample size needed in this study was 115 after being calculated with reference to prior study done [4].

\subsection{Instrument}

The data was collected via interviewed structured questionnaire. The questionnaire consists of three main sections which include socio-demographic data, knowledge, and practice of food safety. Both knowledge and practice components comprise of personal hygiene, food handling and food storage. Total component of knowledge was 12 and one mark was given for the correct answer. Maximum score was 12 and minimum was 0 . Level of knowledge was classified into low level (less than 60\%), moderate level (60$79.9 \%$ ) and high level (80-100\%). Meanwhile, total component of practice was 13. Maximum score was 26 and minimum score was 13 . Level of practice was classified into low level (less than 60\%), moderate level (60-79.9\%) and high level (80-100\%).

\subsection{Data processing and analysis}

Data was entered using Statistical Product and Service Solutions (SPSS) version 22.0. Descriptive statistics were presented to summarize respondents' socio-demographic characteristics, and the prevalence of knowledge and practice on food safety. Chi-square was used to determine the association between knowledge and practice. Meanwhile, multiple linear regression was implemented to identify the associated sociodemographic factors with the practice score on food safety. A p value less than 0.05 were considered as statistically significant.

\section{RESULTS AND ANALYSIS}

\subsection{Characteristics of sample}

In overall, 115 respondents were completed the questionnaires, which make up 100\% response rate. Table 1 indicates characteristics of respondents in Sg Pelek, Sepang. Majority of the respondents were female (55.7\%), Indian (69.5\%), married (63.5\%) and have low education level (no formal school, primary, secondary) (77.4\%).

Table 1. Characteristics of the sample: Socio-demographic, Socio-economic $(\mathrm{N}=115)$

\begin{tabular}{|c|c|c|c|}
\hline Variables & Mean (SD) & Frequency (n) & Percentage (\%) \\
\hline \multicolumn{4}{|l|}{ Socio-demographic } \\
\hline Age & $42.61(15.02)$ & - & - \\
\hline \multicolumn{4}{|l|}{ Gender } \\
\hline Male & & 51 & 44.3 \\
\hline Female & & 64 & 55.7 \\
\hline \multicolumn{4}{|l|}{ Race } \\
\hline Malay & & 4 & 3.5 \\
\hline Chinese & & 31 & 27.0 \\
\hline Indian & & 80 & 69.5 \\
\hline \multicolumn{4}{|l|}{ Marital status } \\
\hline Married & & 73 & 63.5 \\
\hline Non married & & 42 & 36.5 \\
\hline \multicolumn{4}{|l|}{ Education level } \\
\hline Lower (none, primary, secondary) & & 89 & 77.4 \\
\hline Higher (tertiary) & & 26 & 22.6 \\
\hline \multicolumn{4}{|l|}{ Socio-economic } \\
\hline Income & $1000.0(2000.0)^{*}$ & - & - \\
\hline
\end{tabular}

*Median (Interquartile Range)

\subsection{Knowledge and Practice of food safety}

Table 2 represents level of knowledge on food safety. Most of the respondents having moderate level of food safety knowledge; $50 \%(n=57)$, followed by poor knowledge; 35\% ( $n=40)$ (refer to Table 2). 
Table 2. Knowledge of food safety

\begin{tabular}{lcc}
\hline \multicolumn{3}{c}{ OVERALL KNOWLEDGE } \\
\hline \multicolumn{1}{c}{ Variables } & Frequency (n) & Percent (\%) \\
\hline Good & 18 & 15.7 \\
Moderate & 57 & 49.5 \\
Poor & 40 & 34.8 \\
\hline
\end{tabular}

Table 3 denotes level of practice on food safety. Based on table 3, a total of $60 \%(n=69)$ of respondents were having moderate level of food safety practice, followed by poor level of practice; $27 \%$ $(n=31)$.

Table 3. Practice of food safety

\begin{tabular}{lcc}
\hline \multicolumn{3}{c}{ OVERALL PRACTICE } \\
\hline Variables & Frequency $(\mathrm{n})$ & Percent $(\%)$ \\
\hline Good & 15 & 13.0 \\
Moderate & 69 & 60.0 \\
Poor & 31 & 27.0 \\
\hline
\end{tabular}

\subsection{Association between knowledge and practice of food safety} in Table 4).

There is no relationship between knowledge and practice of food safety. The p value was 0.250 (as

Table 4. Association between knowledge and practice of food safety

\begin{tabular}{|c|c|c|c|}
\hline \multirow{3}{*}{ Knowledge } & \multicolumn{2}{|c|}{ Practice } & \multirow{3}{*}{$P$ value } \\
\hline & Good & Moderate \& Poor & \\
\hline & $\mathrm{N}(\%)$ & $\mathrm{N}(\%)$ & \\
\hline Good & 4 (26.7) & $14(14.0)$ & \multirow{2}{*}{0.250} \\
\hline Moderate \& Poor & $11(73.3)$ & $86(86.0)$ & \\
\hline
\end{tabular}

\subsection{Association between socio-demographic factors and food safety practice}

Table 5 showed the association between socio-demographic factors and practice score of food safety. Multiple linear regression revealed there was a significant relationship between gender and food safety practice $(\mathrm{p}=0.048)$ (refer to Table 5$)$. Female has significantly higher score of practice as compared to male by 1.15 (95\% CI: 0.01, 2.29) (in table 5). Furthermore, education level was significantly associated with food safety practice. Higher education level which includes tertiary education has significantly higher score of practice as compared to lower education level (no education, primary, secondary education) by 2.57 (95\% CI: 1.15, 3.99) (in Table 5). With the above two significant variables, the model explained $17 \%$ of variation of the practice score in the study sample $\left(\mathrm{R}^{2}=0.170\right)$.

Table 5. Socio-demographic factors associated with food safety practice

\begin{tabular}{|c|c|c|c|c|c|c|c|}
\hline \multirow[t]{2}{*}{ Variables } & \multicolumn{3}{|c|}{ SLR $^{\mathbf{a}}$} & \multicolumn{4}{|c|}{ MLR $^{\mathrm{b}}$} \\
\hline & $\mathbf{b}^{\mathbf{c}}$ & (95\% CI) & P value & Adj. $b^{d}$ & (95\% CI) & t-stat & P value \\
\hline Age (years) & -0.00 & $(-0.04,0.03)$ & 0.938 & 0.01 & $(-0.03,0.06)$ & 0.62 & 0.535 \\
\hline Gender & 1.56 & $(0.45,2.66)$ & $0.006^{*}$ & 1.15 & $(0.01,2.29)$ & 2.00 & $0.048^{*}$ \\
\hline Race & -0.03 & $(-1.27,1.20)$ & 0.955 & -0.22 & $(-1.45,1.01)$ & -0.35 & 0.723 \\
\hline Marital status & 0.23 & $(-0.94,1.41)$ & 0.695 & 0.43 & $(-0.78,1.65)$ & 0.70 & 0.485 \\
\hline Education level & 2.24 & $(0.95,3.54)$ & $0.001^{*}$ & 2.57 & $(1.15,3.99)$ & 3.59 & $<0.001^{*}$ \\
\hline Income & 0.00 & $(0.00,0.00)$ & 0.302 & 0.00 & $(-0.00,0.00)$ & -1.24 & 0.217 \\
\hline
\end{tabular}

${ }^{\mathrm{a}}$ Simple linear regression

${ }^{\mathrm{b}}$ Multiple linear regression $(\mathrm{R} 2=0.170$; The model reasonably fits well: Model assumptions are met: There is no interaction between independents variables and no multi-collinearity problem)

${ }^{\mathrm{c}}$ Crude regression coefficient

${ }^{\mathrm{d}}$ Adjusted regression coefficient

*Significant at $\mathrm{p}<0.05$

\section{DISCUSSION}

Based on this study, there was high prevalence of respondents having poor and moderate level of knowledge on food safety, which were $35 \%$ and $50 \%$ respectively. This was markedly lower as compared to previous study conducted in Federal Territory of Putrajaya by Ab Hamid et al., in which the respondents 
were found to have good knowledge of food safety with mean score of $90.3 \%$, with benchmark set at $85 \%$ [5]. It was also comparatively lower than the mean score for food handler's knowledge in other study [4].

In contrast, only $13 \%$ of respondents in this study having good practice of food safety. This was lower than prior study done by Ab Hamid et al., where $92.9 \%$ of respondents conducted good practices on food safety [5]. When food handlers did not practice good personnel hygiene or proper handling, they can be the vector for growth of microorganisms through hands, cuts, mouths, skins and hairs [6].

Knowledge on food safety was not statistically significant with food safety practice $(\mathrm{p}=0.250)$. This was contradicted with other studies, where level of food safety knowledge was statistically associated with food safety practice [7],[8]. This indicates that the respondents used to do the right practices although their knowledge is deficient and vice versa. The explanation is maybe due to culture where they practice hygiene and hand washing before eating and preparing foods. A previous qualitative study conducted in Klang Valley stated the respondents had basic knowledge on personal hygiene practice, mainly on hand washing and despite their poor knowledge they have a good practice in personal hygiene [9].

In this study, the results demonstrated there was a significant association between gender and practice score on food safety. Female practiced safety during food handling more as compared to male. This is because female was always involved and responsible for food matters when compared to male. This is supported by previous study, suggested women was more aware of higher levels of threat and concern because they usually have more responsibility for complex decision-making in everyday food preparation and consumption [10]. There was also a significant association between educational level and food safety practice score. Higher education level holder was practiced better than those with lower education level. This is compliant with previous study conducted by Ab. Hamid [5], among hawkers in Putrajaya with significant difference between mean score on practices and education level for Malaysians $(\mathrm{p}=0.003)$. The result shows that lower educational level have an effect in food safety practice. Therefore, people with higher education will practice better on food safety.

This study had several limitations. Firstly, there is population bias, where the residents of Taman Bahagia are mostly Indian and Chinese. Thus, the risk factor for race is not reliable. Furthermore, there are interviewer biases. The survey was conducted by several interviewers at the same time. The opinion or prejudice on the part of the interviewer may occur where they may ask the question in a way that will affect the respondent understanding and result outcome.

Residents in Taman Bahagia Sg. Pelek, Selangor need to improve their education level and improve their understandings on food safety. Health clinics are encouraged to do follow up and giving exposure to health education from time to time so that they will always be reminded. Moreover, male is advised to involve themselves more often in food handling to properly engage with food safety, as practice make perfects.

\section{CONCLUSION}

The result of this study showed a moderate and poor level of knowledge and practice of food safety. Socio-demographic factors associated with food safety practices include gender and education level. It is recommended to have a higher education level and inculcate a good food safety practice in order to eradicate food poisoning and promote healthier living.

\section{ACKNOWLEDGEMENTS}

We acknowledge and are grateful for the financial help furnished by Cyberjaya University College of Medical Sciences (CUCMS). We are also acknowledging the residents of Taman Bahagia, Sg. Pelek, Sepang as the respondents of this study as well as the students of CUCMS as the data collectors. Also, other members of this research group namely Nadia Shahira Azmi, Siti Nur Amalina Farhan Abd Aziz, Nurathirah Senin, and Burhanuddin Hilmi Mohd Sharani.

\section{REFERENCES}

[1] Mustaffa, AM., "Contamination, Adulterations, and Chemicall Residues in Malaysian Food: Past, Present and Future”, Malaysian Journal of Public Health Medicine, vol. 11, 2011.

[2] Health Facts, Ministry of Health Malaysia, 2014.

[3] World Health Organization, "WHO Initiative to Estimate the Global Burden of Foodborne Diseases. A Summary Document”, 2008. $\quad$ Retrieved August 2014 from http://www.who.int/foodsafety/foodborne_disease/Summary_Doc.pdf. 
[4] Azira, N., Faid, M., Mustafa, S., Syafinaz, R., Malina, "Knowledge, Attitude and Practices Regarding Food Hygiene and Sanitation of Food”, Food Control , vol. 27, pp. 289-293, 2012.

[5] Ab. Hamid, R., Radu, S., Othman, M., Toh, PS., Chai, LC., “Assessment of Knowledge, Attitude and Practices Concerning Food Safety among Restaurant Workers in Putrajaya, Malaysia”, Food Science and Quality Management, vol. 32, 2014.

[6] Bryan, F., "Risk of Practices, Procedures and Processess That Lead to Outbreaks of Foodborne Diseases", Journal of Food Protection, pp. 663-673, 1988.

[7] Gizaw, Z., Gebrehiwot, M., Teka, Z., "Food Safety Practice and Associated Factors of Food Handlers Working in Substandard Food Establishment in Gondar Town, Northwest Ethiopia”, International J Food Sci Nutr Diet, vol/issue: 4(5), pp.138-146, 2014.

[8] Labib, S., Mohammad, MO., Mohammad Raed, AD., "Food Hygiene Knowledge, Attitudes and Practices of the Food Handlers in the Military Hospitals”, Food and Nutrition Sciences, pp. 245-251, 2013.

[9] Tan, SL., Cheng, PL., Soon, HK., Ghazali, H., Mahyudin, NA., "A Qualitative Study on Personal Hygiene Knowledge and Practices among Food Handlers at Selected Primary Schools in Klang Valley Area, Selangor, Malaysia”, International Food Resrach Journal, vol/issue: 20(1), pp. 71-76, 2013.

[10] Worsley, AW., Wei C.,Hunter, W., "Gender differences in the influence of food safety and health concerns on dietary and physical activity habits”, Food policy, vol. 41, pp. 184-192, 2013. 